\title{
COMPUTATIONAL FLUID DYNAMICS SIMULATION OF SINGLE SCREW EXTRUDERS IN CABLE INDUSTRIES
}

\author{
Baalaganapathy Manohar ${ }^{1}$, Periasamy $\mathbf{C}^{2}$ \\ ${ }^{1}$ Student in 4th Year, Mechanical Engineering Department, BITS Pilani, \\ ${ }^{2}$ Professor, Mechanical Engineering Department, BITS Pilani
}

\begin{abstract}
The flow of polymer pellets along the solid conveying screw of a single screw extruder is studied by use of a numerical model based on the Finite Volume Method (FVM). The screw profile of existing Nokia-Malifer plastic extrusion devices (for cable industries) was mesured.Model predictions used is the Power law for Non-Newtonian Fluid, the results are compared with experimental data, showing a good match. The feasiability of using CFD models for designing plastic extrusion devices is analyzed. Basic parameters such as temperature, velocity profiles and pressure show high degree of similarity to practical results.
\end{abstract}

KeyWords: CFD, Single Screw Extruder, Ansys Fluent, Numerical Simulation

\section{INTRODUCTION}

Plastics extrusion is a manufacturing process in which plastic pellets are melted and formed into continuous profiles.

An extruder has five distinct goals or objectives to achieve in the extrusion process :

- To provide correct temperature for polymer tpmelt properly without burning

- Maintain the constant melt temperature that was achieved initially

- To find the correct melt pressure required in the die

- Maintain an uniform melt pressure in the die

- To produce a well-mixedhomogeneous,polymer product

Table 1: Dimension of screw

\begin{tabular}{|l|l|l|l|l|}
\hline \multicolumn{4}{|l|}{ Flighted length $=1600 \mathrm{~mm}$} \\
\hline \multicolumn{4}{|l|}{$/ \mathrm{D}=10.12$} \\
\hline Compression Ratio=1.8 \\
\hline & $\begin{array}{l}\text { Helical } \\
\text { pitch } \\
(\mathrm{mm})\end{array}$ & $\begin{array}{l}\text { Length } \\
(\mathrm{mm})\end{array}$ & $\begin{array}{l}\text { Outer } \\
\text { diameter } \\
(\mathrm{mm})\end{array}$ & $\begin{array}{l}\text { Shaft } \\
\text { diameter } \\
(\mathrm{mm})\end{array}$ \\
\hline Feed & 80 & 320 & 158 & 98 \\
\hline Transition & 50 & 630 & 158 & $98-125$ \\
\hline Metering & 90 & 650 & 158 & 125 \\
\hline
\end{tabular}

Any plastic extrusion device consists of 5 important componenets :

- $\quad$ Feed system

- Head and die assembly

- $\quad$ Drive system

- Control system

- $\quad$ Screw, barrel, and heaters system

For the purpose of analysis on Screw,barrel and heaters system are consdiered.[1][2]

\section{INTRODUCTION ON SCREW}

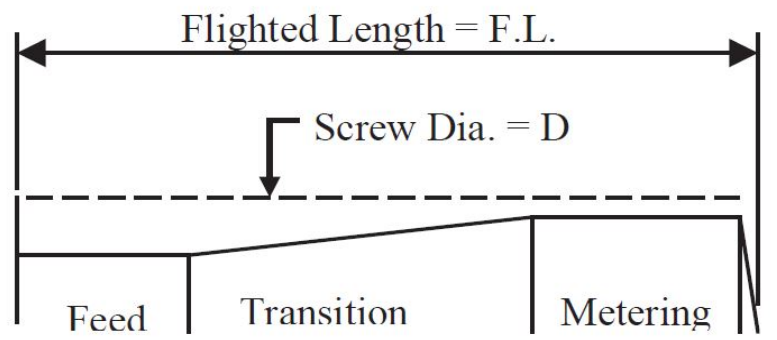

Fig 1: Screw dimension

\subsection{Metering Section}

The metering or pumping section of the screw is where the melting of the polymer is completed and pumping to overcome the headpressure takes place.[3]

$$
\text { Rat }=2.3 * D^{2} * h_{m} * S G * N
$$

Rate $=$ throughput $(\mathrm{lb} / \mathrm{hr})$

$\mathrm{D}=$ Screw Diameter (inches)

$h_{m}=$ Metering Depth (inches)

$\mathrm{SG}=$ Specific Gravity of Polymer (gm/cc)

$\mathrm{N}=$ Screw Speed (RPM)

Compression Ratio

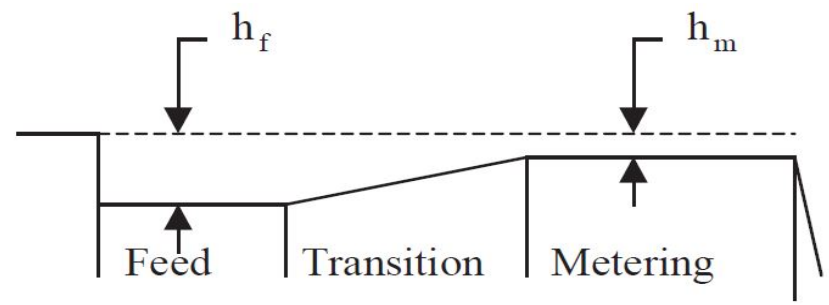

Fig 2: Compression ratio

$$
\text { Compression Ratio }=\frac{h_{f}}{h_{m}}
$$

The moddeled groove profile is as show in figure 2 


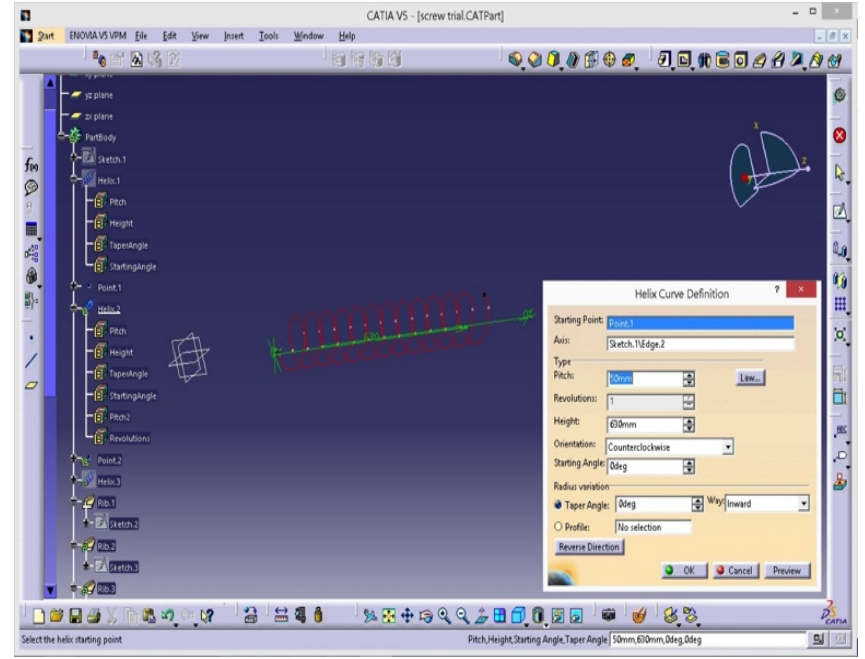

Fig 3: Helix construction

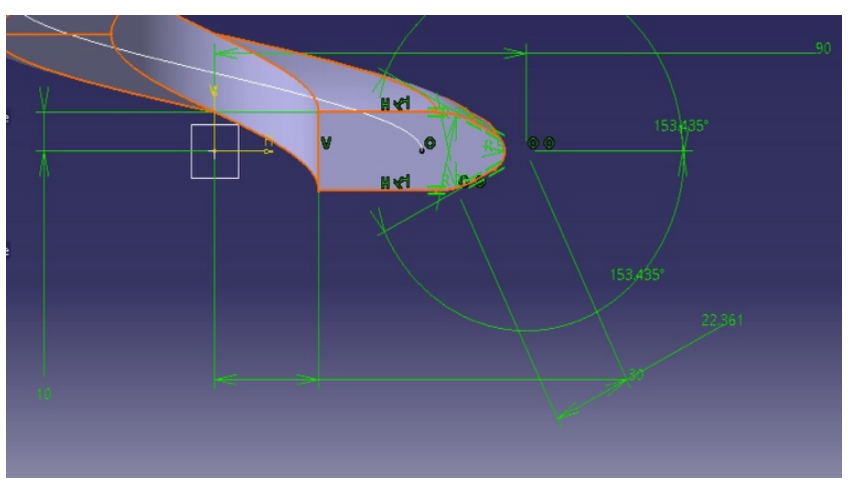

Fig 4: Groove profile

The following image clearly show the difference in pitch angle between the three section of the screw. The first feed section has the grooves fairly evenly spaced due to pitch of $80 \mathrm{~mm}$. In the transition section the grooves are closely spaced to each other. It has a pitch of $50 \mathrm{~mm}$. This hepls to provide some back pressure as well as to help mix the polymer evenly. The Metering section the grooves are spaced far from each other. This helps reduce the pressure and also to reduce the velocity in the section as the molten polymer has to exit.[4]

\section{POLYMER USED}

In this research the insulation material used is a crosslinkable low density polyethylene, XLPE 4201 supplied by Borealis. This material has been used for over 20 years for insulation of medium and high voltage cables and is still used by most of the major cable manufacturing corporations. Main advantages of cross-linking polyethylene over the standard LDPE are: good scorch resistance, good aging performance, resistance to water tree-ing, good insulation properties, low exudation of peroxide and antioxidance and cleanliness.

First the temperature in the barrel is confirmed by cross checking with existing experimental data of Cross linking and melting temperatures.[5]

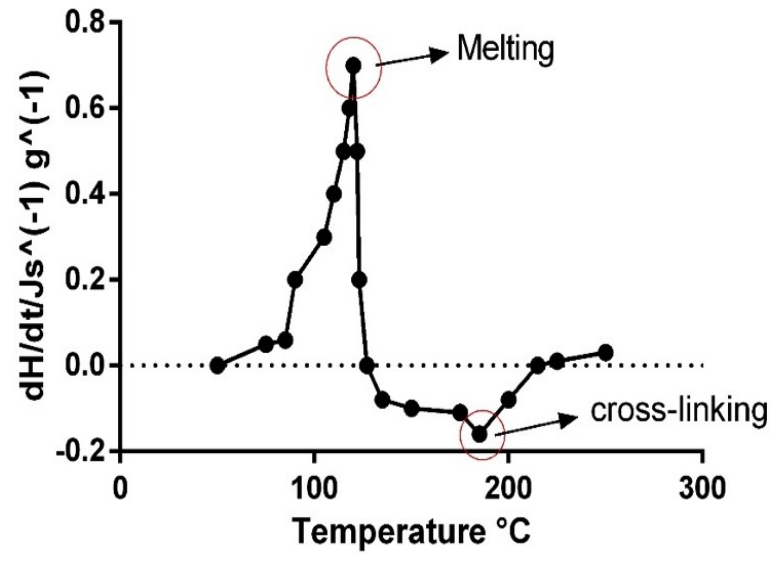

Table 2 shows other properties of xlpe at fixed temperature

\begin{tabular}{|c|c|c|c|c|c|}
\hline \multirow{2}{*}{$\begin{array}{l}\text { XLPE } \\
4201 \\
\text { (Boreal } \\
\text { is) } \\
\text { properti } \\
\text { es }\end{array}$} & \multicolumn{3}{|c|}{ of $200^{\circ} \mathrm{C}$} & \multirow[b]{2}{*}{$\begin{array}{l}\text { Viscosi } \\
\text { ty } \\
\text { (Kg/m- } \\
\text { s) }\end{array}$} & \multirow[b]{2}{*}{$\mathrm{n}$} \\
\hline & $\begin{array}{l}\text { Densi } \\
\text { ty } \\
(\mathrm{Kg} / \\
\left.\mathrm{m}^{3}\right)\end{array}$ & $\begin{array}{l}\text { Specif } \\
\text { ic } \\
\text { Heat } \\
(\mathrm{J} / \mathrm{Kg}- \\
\mathrm{K})\end{array}$ & $\begin{array}{l}\text { Thermal } \\
\text { Conductiv } \\
\text { ity } \\
(\mathrm{W} / \mathrm{m}-\mathrm{K})\end{array}$ & & \\
\hline & 930 & 2045 & 0.3 & 7 & $\begin{array}{l}0.5 \\
8\end{array}$ \\
\hline
\end{tabular}

Assumption for simplification of Model:

The following assumptions are made for the model:

1. The polymer fluid is incompressible, and has apseudo plastic characteristic.

2. The RPM of the screw rotation is very low, so the polymer fluid flow is laminar. Also there is no slippage between fluids and the cylinder wall.

3. Only the viscousfluid forces are concerned, inertial force and gravity are neglected as they are miniscule

4. The fluid is assumed as completley homogeneous and the flow and heat transfer as steady state and quasi threedimensional.

5. Multiphase phase flow has not been considered for the polymer

\section{SOLVER MODEL USED}

The model used for the analysis is Power-law fluid relationship. This model approximately describes the behaviour of a real non-Newtonian fluids.[6]

The material constitutive equation is:

$$
\eta_{\min }<\eta=k \gamma^{n-1} e^{T_{0} / T}<\eta_{\max }
$$

$k \quad$ is a measure of the average viscosity of the fluid (the consistency index);

$n$ is a measure of the deviation of the fluid from Newtonian (the power-law index), as described below;

$T_{0} \quad$ is the reference temperature;

$\eta_{\min }$ and $\eta_{\max }$ are, respectively, the lower and upper limits of the power law. 


\section{BOUNDARY CONDITIONS}

The model was made in Ansys in design workbench. A boolean operation was carried out to remove the screw from the barrel therby giving the fluid portion. The barrel was split into 3 portion to supply heat from the 3 heating coils individually and these were named as zone1, zone 2 and zone3

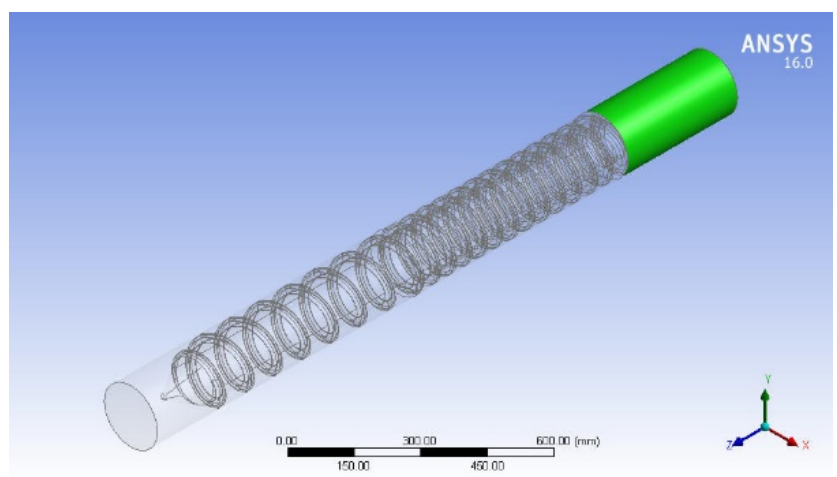

Fig 7: Zone 1

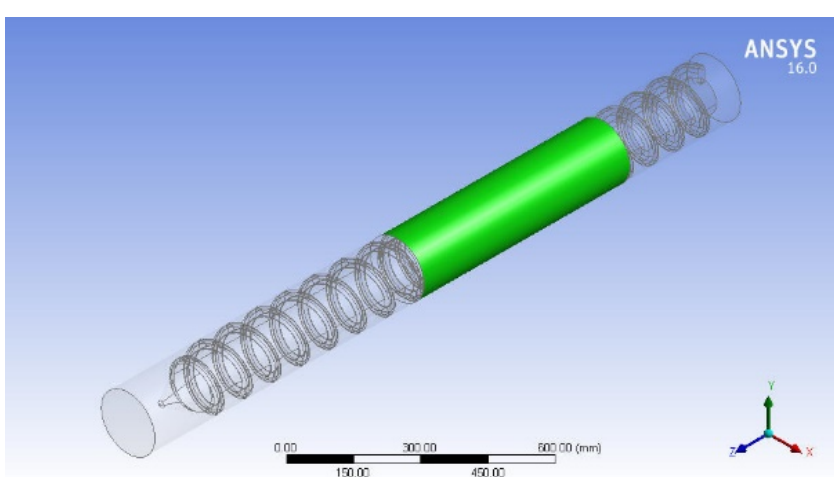

Fig 8: Zone 2

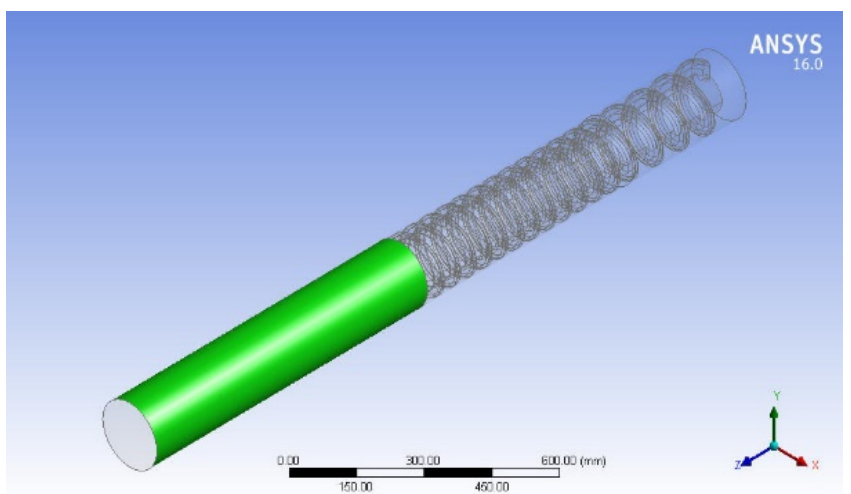

Fig 9: Zone 3

A very fine mesh was used as CFD analysis of Non newtonion fluid approch ideal values at such large numbers of mesh nodes. The final mesh contained 2,964,227 elements and 628,915 nodes.

For the boundary condition, the screw velocity was given as $12 \mathrm{rpm}$. A back pressure due to the wired mesh at the exit has been measured practically at 110 bars. The target mass flow rate of the machine is $0.065 \mathrm{Kg} / \mathrm{s}$. The three heater band values are mentioned in the table below.[7], [8]

\begin{tabular}{|l|l|l|l|}
\multicolumn{1}{|c|}{} & $\begin{array}{l}\text { Temperature } \\
(\mathrm{K})\end{array}$ & $\begin{array}{l}\text { Heat } \\
\text { Generation } \\
\left(\mathrm{W} / \mathrm{m}^{3}\right)\end{array}$ & $\begin{array}{l}\text { Wall } \\
\text { Thickness } \\
(\mathrm{mm})\end{array}$ \\
\hline $\begin{array}{l}\text { Zone } \\
1\end{array}$ & 468 & 164 & 40 \\
\hline $\begin{array}{l}\text { Zone } \\
2\end{array}$ & 478 & 93.5 & 40 \\
\hline $\begin{array}{l}\text { Zone } \\
3\end{array}$ & 489 & 64.72 & 40 \\
\hline
\end{tabular}

\section{RESULTS AND DISCUSSION}

As can be seen from Fig 10 the pressure keeps decreasing as the fluid keeps reaching the outlet and finally is exposed to the atmosphere. The pressure is obtained due to the profile of the screw and also due to the rotation of the screw.

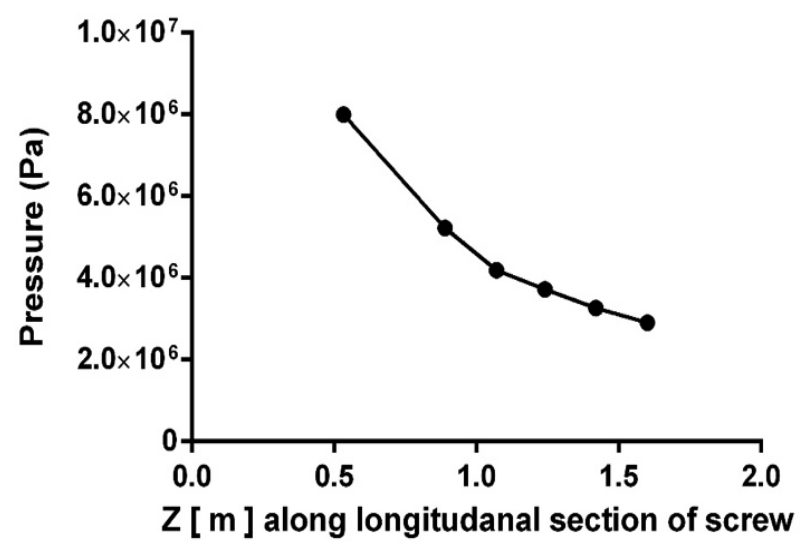

Fig 10: Pressure along longitudanal section of the screw

The temp profile is as expected. The final temperature of the fluid is $477 \mathrm{~K}\left(204^{\circ} \mathrm{C}\right)$ well over the cross linking temperatrue of $463 \mathrm{~K}\left(190^{\circ} \mathrm{C}\right)$ This is also close to the practical value of temperature of molten polymer at $212^{\circ} \mathrm{C}$

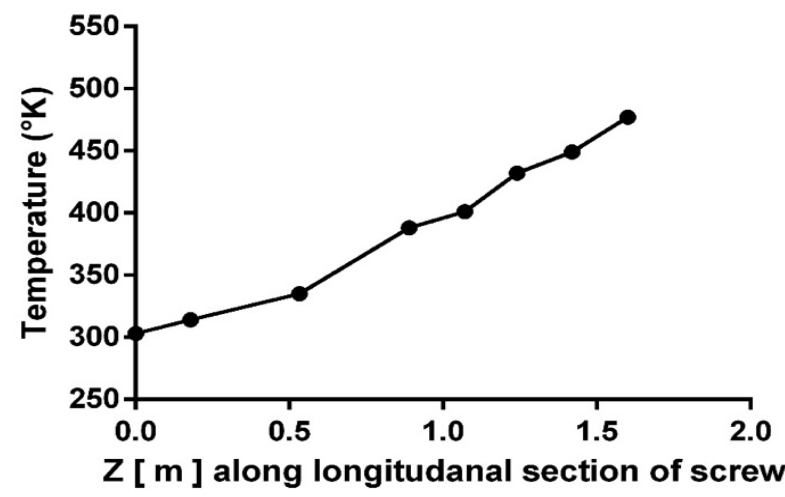

Fig 11: Temperature along longitudanal section of screw

The velocity along the longitudanal section has a high to $1.14 \mathrm{~m} / \mathrm{s}$. This high speed is attained in the transition section. Not only do the tightly spaced grooves help maintain high pressure in the feed section but also helps increase the rate of mixing the polymer. While the actual 
max velocity cannot be determined for cross checking due to it being present in the transition section the result of the exit pressure is similar to that of practically obtained velocity. The value can be seen in Fig 12

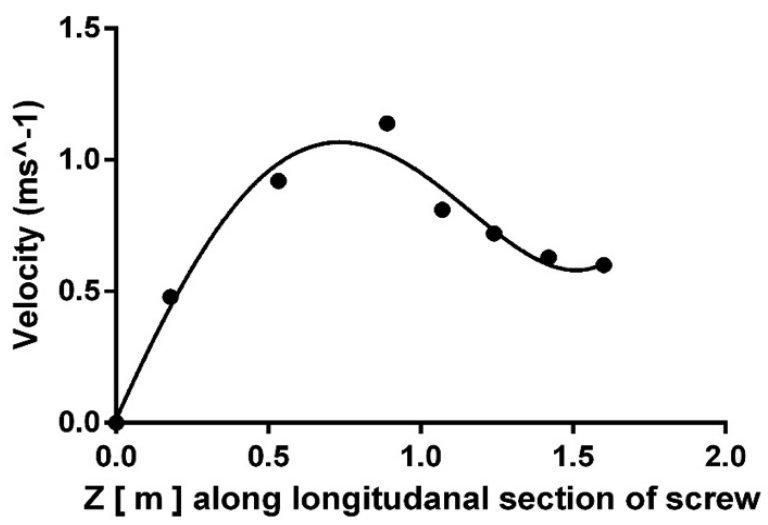

Fig 12: Velocity along longitudanal section of screw

For futher analysis series of lateral imagianry lines need to be drawn on the extruder. The varition of temperatrue is across theese lateral lines are plotted.

\begin{tabular}{|l|l|l|l|l|l|l|l|}
\hline $\begin{array}{l}\text { Name of } \\
\text { the } \\
\text { location }\end{array}$ & $2 \mathrm{x}$ & $3 \mathrm{x}$ & $4 \mathrm{x}$ & $5 \mathrm{x}$ & $6 \mathrm{x}$ & $7 \mathrm{x}$ & $8 \mathrm{x}$ \\
\hline $\begin{array}{l}\text { Distance } \\
\text { from } \\
\text { origin } \\
\text { (mm) }\end{array}$ & 0 & 160 & 320 & 635 & 950 & 1275 & 1600 \\
\hline
\end{tabular}

Table

From Fig 13 it can be inferred that temperature of polymer near the screw surface and near the barrel wall is the highest. The polymer material in middle is of lower temperature. This leads to sticking on the screw and finally results in machine break down.

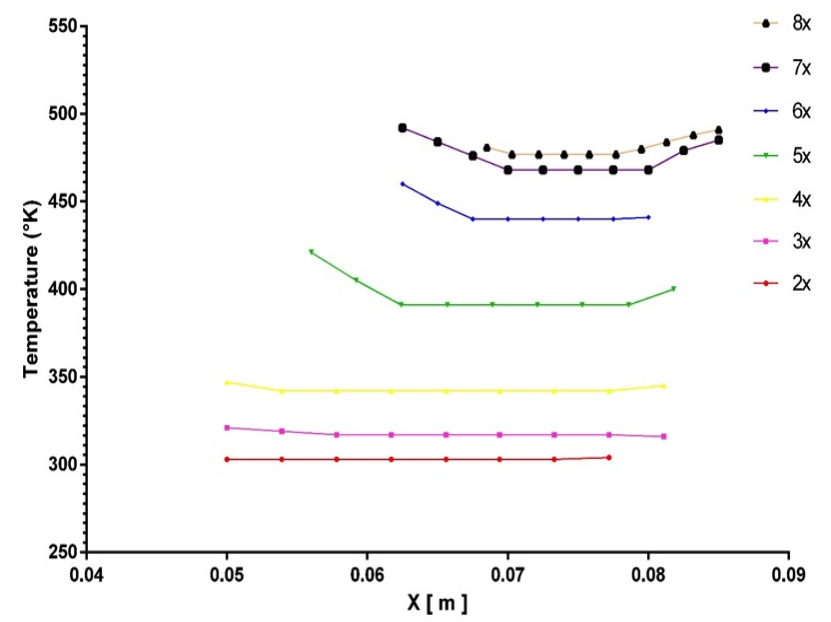

Fig 13:Lateral Temperatrue Profile

\section{CONCLUSION}

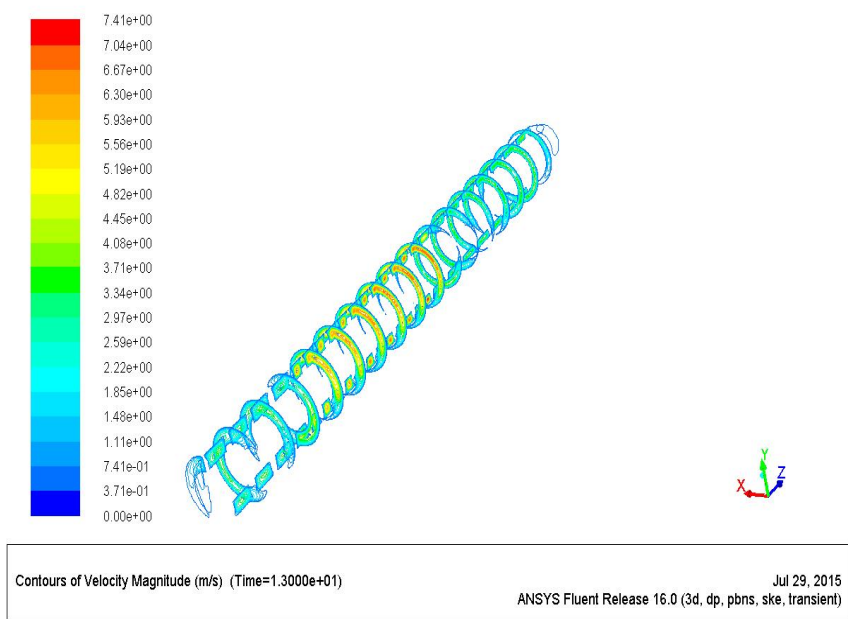

Fig 14: Velocity Contour

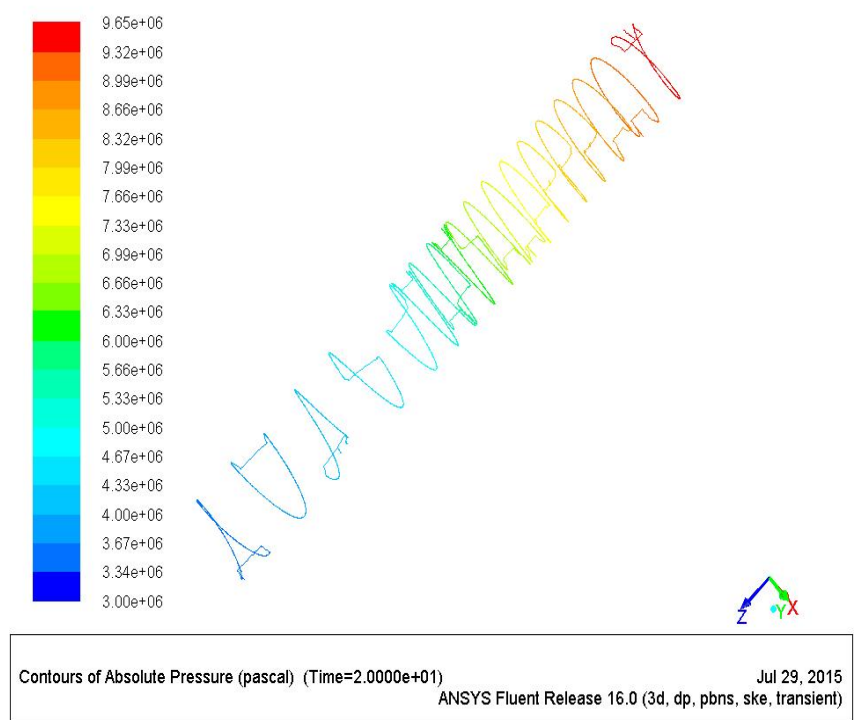

Fig 15: Absolute Pressure Contour

It can be seen from the result obtained in the graph that the numerical values obtained are in close proximity with that of practical values in the extruder. The research succesfully validates the use of CFD for design of the extruder screw and barrel. More research needs to be done specially on how to avoid breakdown from occuring due to materials being stuck on the walls.

\section{BIBILOGRAPHY}

[1]. M. Gale, Mixing in Single Screw Extrusion. .

[2]. C. J. . Stevens M.J, Extruder Principles and Operation.

[3]. T. W. Womer, "Basic Screw Geometry," 2003.

[4]. A. Kuhne, "3 Single Screw Extruder : Equipment," pp. 17-46, 2014.

[5]. V. Kosar and Z. Gomzi, "Modeling of the power cable production line," vol. 457, pp. 70-82, 2007.

[6]. S. A. Patel and R. P. Chhabra, "Laminar Free Convection in Bingham Plastic Fluids from an 
Isothermal Elliptic Cylinder," J. Thermophys. Heat Transf., pp. 1-16, 2015.

[7]. J. M. Buick and J. A. Cosgrove, "Numerical simulation of the flow field in the mixing section of a screw extruder by the lattice Boltzmann model," vol. 61, pp. 3323-3326, 2006.

[8]. M. V. C. Alves, J. R. B. Jr, and A. T. Prata, "Analytical solution of single screw extrusion applicable to intermediate values of screw channel aspect ratio," J. Food Eng., vol. 92, no. 2, pp. 152-156, 2009.

\section{BIOGRAPHIES}

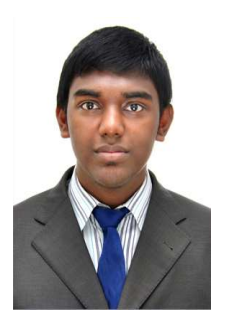

Baalaganapathy Manohar is an undergraduate student in BITS Pilani Dubai Campus. $\mathrm{He}$ will complete his undergraduate degree in July 2016 and hopes to pursue his graduate admission in U.S with specialisation in Fluids and Heat Transfer . He is currently a teaching assistant for the Computational Fluid Dynamics course with sound knowledge in Ansys packages and has completed projects related to tribology,Numerical simulation of fluid flow in screw extruders and design analysis of carbon nano tube composite aircraft wings. While not in university he enjoys composing music and cooking.

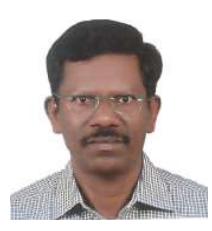

Dr. C. Periasamy, was born in 1959 . He obtained Ph.D degree in Mechanical Engineering from Department of Mechanical and Aerospace Engineering, Case Western Reserve University, Ohio, USA. His specialization is Fluid Dynamics and Thermal Science. He is working as Professor in the Department of Mechanical Engineering, BITS Pilani Dubai Campus, Dubai, UAE. His research interest includes Computational Fluid Dynamics, Combustion, Heat and Mass Transfer, Multiphase Flows. He is the peer reviewer of Journal Applied Fluid Mechanics and Journal of the International Measurement Confederation. He is a member of Indian Society of Technical Education, Indian Society for Heat and Mass Transfer, Aeronautical Society of India, Fluid Mechanics and Fluid Power and Indian Welding Society 